\title{
PP in 3D Printing - Technical and Economic Aspects
}

\author{
IONEL DANUT SAVU ${ }^{1}$, SORIN VASILE SAVU' ${ }^{1}$, DALIA SIMION ${ }^{1}$, NICUŞOR-ALIN SÎRBU ${ }^{2 *}$, \\ MIRELA CIORNEI ${ }^{3}$, SORIN AUREL RATIU ${ }^{4 *}$ \\ ${ }^{1}$ University of Craiova, $13^{\text {th }}$ A.I. Cuza Str., 200585, Craiova, Romania \\ ${ }^{2}$ NRDI for Welding and Material Testing, 30 ${ }^{\text {th }}$ Mihai Viteazu Str., 300222, Timișoara, Romania, ISIM Timișoara, \\ ${ }^{3}$ Territorial Labor Inspectorate of MH / Inspectoratul Teritorial de Muncă MH, $3^{\text {rd }}$ Carol I Str., 220099, Drobeta Tr. Severin, \\ România \\ ${ }^{4}$ Polytechnic University of Timisoara, Faculty Engineering of Hunedoara, 5 Revolutiei Str., Hunedoara, 331128, Romania
}

\begin{abstract}
FDM is 3D printing technology using mainly PLA and ABS as filament materials. PP has close characteristics to PLA and, due to that, is a potential material for for deposition. Paper aims to analyse the behaviour of PP during heating cycle specific to $3 D$ printing process. Macroscopic and microscopic analysis of the deposited strings have been performed. They revealed less stiffness of the PP deposition comparing to PLA, which is due to the lower viscosity of PP. DSC Thermal analysis has been done at it revealed a $30 \%$ higher heat flux in PP comparing to PLA and that increases its fluidity. It was recorded a difference between the elongation viscosity of the PP filament and the PP deposited by FDM process. After $5 s$ the deposited PP proves higher values for the elongation viscosity. Dynamic shear rheology measurements the was applied on samples deformed under $210 \mathrm{kN}$ at $190^{\circ} \mathrm{C}$. It has been found that the PP requires lower storage energy and that means that it has a lower viscosity for the entire range of applied frequencies. In the same time, the complex viscosities prove different behavior. To improve the control of the deposition shape, it is necessary to reduce the extrusion temperature with 4$5 \%$. That leads to economy in power consumption.
\end{abstract}

Keywords: PP filament, DSC analysis, dynamic shear rheology measurement, storage modulus, complex viscosity, elongation viscosity

FDM 3D printing is technology often applied for rapid erection of different types of products, from prototypes (single primary product) to production (not mass, but limited) [1-4]. The named technology uses polymers or metals, in different shapes (filament, powder, pool, etc.), to generate layer over layer until the shape and the dimensions of the piece to be produced are reached [2-4]. The additive process is, generally, regulated by EN ISO/ASTM 52900:

Additive manufacturing. General principles. Terminology 2017

$3 \mathrm{D}$ technology is continuously finding new application in various domains and the literature of the last decade gave the measure of the 3D technology's importance [2, 5 6]. Zapciu [7] reported the design and prototyping of several 3Dprintable mechanisms which are designed to be pneumatically actuated, as a potentially cheaper and more widely accessible alternative to existing solutions. He produced the prototypes from thermoplastic materials using Fused Deposition Modeling (FDM). Motomancea [8] concluded that the 3D scanning permits the fabrication of digital which can be lately 3D-printed. The 3D printing allows rapid fabrication of duplicates starting from a prototype with acceptable size accuracy. The results of Fabian [9] showed that the MED610 biocompatible material is a good choice for 3D printing of specific medical devices dedicated to surgery. The method which he applied brought added value to the secondary cleft surgery, by increasing the volumetric precision of the bone-graft and, more, the increasing of its density. Tarnita [5] used the 3D technology and high-performance composite powder to produce physical prototypes of orthopaedic implants and complex functional prosthetic systems. She applied the prototypes in ,in vitro" experimental tests, obtaining important improvements in prosthetics.

In parallel with the development of new applications, research on the improvements of the materials to be added has been conducted. The most used consumables are ABS and PLA, but PETG, PP, Nylon, Carbon fiber, ASA and even PE cpuld be used. Dimonie [10] considers that starch presents good potential to be used in polymer technology, and the FDM method of 3D printing is appropriate to involve starch based-compounds as deposited material. Trhlíková [11] used the step transient method to evaluate the properties of different types of PLA and PP and ABS materials from 3D printing fillaments, and she determined all the required parameters using a fractal heat transfer model. Vasilescu [6]

*email:alin_sirbu@yahoo.com,asirbu@isim.ro; sorin.ratiu@fih.upt.ro 
reported specific deviations of the obtained dimensions from the design, due to thermal expansion and contraction of the used material. Other results [12-16] showed that the semi-crystalline polymers present similar deformation behaviour (yielding, strain softening or hardening) as mainly of the amorphous polymers. Each modification influences the polymer behaviour during the 3D printing process. The deformation behaviour is significantly influenced by the crystallinity and by the lamellar thickness, according to Van Erp [12]. He reported in its Master thesis that a higher degree of crystallinity and an increase of lamellar thickness produce an important increasing of the yield stress. Jeřábek [17] analysed the ways of loading of a polymeric material used in engineering applications and he concluded that material is multiaxial loaded and beside tensile loads the compressive stresses proved to be dominant. The polymer he used was the PP and he obtained a linear correlation between the equivalent stress and the mean stress for different test temperatures. The results of Gleiter [18] showed that at low temperatures plastic deformation occurs by slip only, which is different from the high temperatures where the deformation processes are thermally activated. Séguéla [19] and Wilhelm [20] and Hirsch [21] and Boyd [22] reported that the crystallographic processes are active at any strain level, since the melting recrystallization is limited to the post-yield in conjunction with the chain unfolding (being more a result of chain unfolding than a mechanism of the plastic deformation). Hirsch [21] estimated the contribution of the crystalline part of the PP to its plastic flow. The flowing of the PP during the welding process and its behaviour in electric applications were reported by Chinnadurai [23], Chi [24] and Cicic [25]. Both of them revealed a decrease in plasticity during heating and cooling cycles. Such behavior was confirmed by Maries [26], Bolocan [27], Savu [28,29] and Rapa [30], the last confirming, also, that the melt viscosity is given as the ratio of shear stress to shear rate. All the reported results confirm various modifications of the characteristics of PP after a thermal cycle consisting of heating plus cooling, even if the polymeric material is a composite [31]. That means that using of PP filaments involves specific issues during the additive process. Analysis of those issues is required, if decide to replace the „classic" materials dedicated to 3D printing that are PLA and ABS. Also, information regarding the economic aspects of the introduction of PP as filler material is important to be known.

Starting with these, the paper presents comparative analysis of using the ABS and the PLA on the one hand and the PP on the other hand. The technical comparison regards the modifications of crystallization and the flowing parameters. The economic analysis regards the comparison between the involved costs for the two situations. Before any comparison is important to remind the characteristics of PP:

- It has $60-70 \%$ crystallinity degree

- Its density is $900-1000 \mathrm{~kg} / \mathrm{m}^{3}$

- Melt Flow Index $\left(2.16 \mathrm{~kg} / 230^{\circ} \mathrm{C}\right)$ acc. to ASTM D1238: $8 \mathrm{~g} / 10 \mathrm{~min}$

- Tensile Strength / Elongation at Yield acc. to ASTM D638: $25 \mathrm{~N} / \mathrm{mm}^{2} / 20 \%$

- Charpy Notched Impact Strength (at $-20^{\circ} \mathrm{C}$ ) acc. to DIN 53453: $7.2 \mathrm{~mJ} / \mathrm{mm}^{2}$

- Flexural Modulus (1\% SECANT) acc. to ASTM D790: $1130 \mathrm{MPa}$

- $\quad$ Rockwell Hardness acc. to ASTM D785: 87 R-Scale

- Heat Distortion Temperature (Load $0.45 \mathrm{~N} / \mathrm{mm}^{2}$ ) acc. to ASTM D 648: $92{ }^{\circ} \mathrm{C}$.

Regarding the use in 3D printing, the filament is pushed by specific feeder to the heating nozzle and, subsequently, to the melting area. That means that the filament should have appropriate stiffness to allow the feeder to push it without deformation which could block the filament into the nozzle. In the same time, the filament material should have good strength in order to give to the product appropriate mechanical resistance. The filament material should have as low as possible density, in order to have high length for a specific quantity of material and for a specific diameter. Last but not least, the filament material should have low price, because an important component of the product's price is related to the filament's price. Table 1 presents few characteristics of the PP, ABS and PLA materials, characteristics which are relevant for the use in the $3 \mathrm{D}$ printing process.

Table 1

COMPARISON OF THE MAIN CHARACTERISTICS

\begin{tabular}{|c|c|c|c|}
\hline & $\mathbf{P P}$ & ABS & PLA \\
\hline \multicolumn{4}{|c|}{ Mechanical properties and characteristics } \\
\hline Yield stress [Unit] ([MPa]) & $\begin{array}{l}1 \\
(32)\end{array}$ & $1,25(40)$ & $2,00(64)$ \\
\hline Stiffness [Unit] & 1 & 1,25 & 1,85 \\
\hline Lifetime [Unit] & 1 & 0.9 & 0.45 \\
\hline $\begin{array}{l}\text { Max temperature in service } \\
\text { [Unit] }\left(\left[{ }^{\circ} \mathrm{C}\right]\right)\end{array}$ & $1(100)$ & $0.95(95)$ & $\begin{array}{l}0.5 \\
(0.5)\end{array}$ \\
\hline \multicolumn{4}{|c|}{ Physical properties and characteristics } \\
\hline $\begin{array}{l}\text { Specific mass } \\
\left(\left[\mathrm{g} / \mathrm{cm}^{3}\right]\right)\end{array}$ & $\begin{array}{l}1 \\
(0.9)\end{array}$ & $\begin{array}{l}1.17 \\
(1.05) \\
\end{array}$ & $\begin{array}{l}1.40 \\
(1.25) \\
\end{array}$ \\
\hline $\begin{array}{c}\text { Coefficient of } \\
\text { Expansion [Unit] }\left(\left[\mu \mathrm{m} / \mathrm{m} /{ }^{\circ} \mathrm{C}\right]\right)\end{array}$ & $1(150)$ & $0.6(90)$ & $0.45(67)$ \\
\hline \multicolumn{4}{|l|}{ Economic aspect } \\
\hline Average price [Unit] (EUR) & $\begin{array}{l}1 \\
(80)\end{array}$ & $0.25(20)$ & $0.25(20)$ \\
\hline
\end{tabular}


It can be observed in Table 1 that the strength of PP is lower than the strength of ABS and PLA, but PP compensates the difference by longer lifetime. The stiffness of PP is similarly lower, but PP compensates the named difference by lower specific mass and that means that for the same quantity of material and for the same diameter, the PP filament is longer. Economically speaking, the PP filament is 4 times more expensive than ABS or PLA.

\section{Experimental part}

Materials and equipment

To evaluate the behaviour of PP during a thermal cycle which is specific to the 3D printing, it was used filament of RA130E which is a high molecular weight polypropylene random copolymer (PP-R) compound, produced by extrusion of heated granules composed of polypropylene homopolymer, manufactured and delivered by Borealis Polyolefine $\mathrm{GmbH}$. RA130E had a melt flow rate (MFR) around $0.3 \mathrm{~g} / 10 \mathrm{~min}$ (ISO 1133, at $230^{\circ} \mathrm{C}$ ). In the same time commercial PLA filament was used in the same conditions as reference. The both filaments were used to erect specific pieces by 3D printing, using Da Vinci 2.0 printer.

When use in 3D printing, the melted material is forced to cross a narrow section which is specific to the active nozzle of the printer [32] (figure 1). That means that a modification of the pressure is acting on the material. In this case it is important to know how the modification of the pressure influences the shear stress and the viscoelasticity during the 3D printing process.

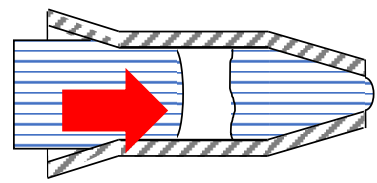

Fig. 1. Modification of the melt filament section in 2 stages

\section{Macroscopic analysis}

Compared to the extruded and deposited PLA filament, the deposited PP seems to be less viscous, even if the melting points are almost similar. PLA shows stiffness and direction, while PP is soft and difficult to control (figure 2). As deposited material, the PLA's strings show similar melting, they keep linear direction (according to the printer movement), while the PP's strings show areas of "over-melting" heating (figure 3). Solutions to increase the control could be the decreasing of the extrusion temperature or the doping of the PP to increase its stiffness.

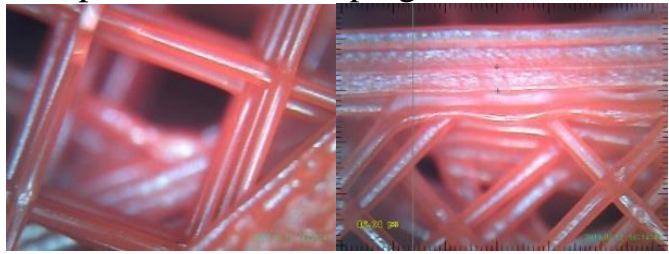

a. b.

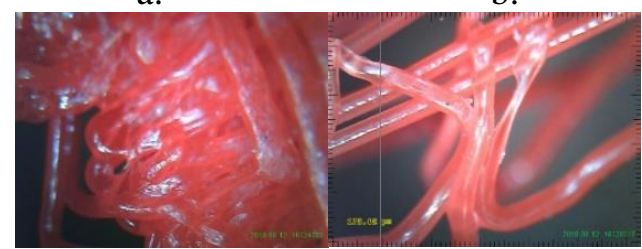

c.

d.

Fig. 2. Extruded PLA(a,b) and $P P(c, d)$ at $188^{\circ} \mathrm{C}$

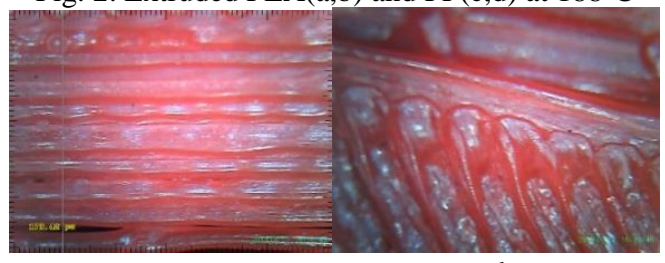

a.

b.

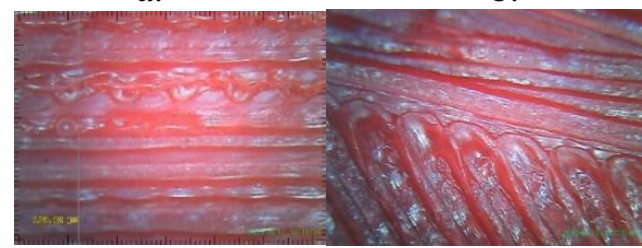

c.

d.

Fig. 3. Deposited strings of PLA(a,b) and PP(c,d) at $188^{\circ} \mathrm{C}$ 


\section{Thermal analysis}

The filament material and the deposited material were analysed by using Differential scanning calorimetry (DSC, STARe DSC822e). It was evaluated the melting and the evolution of the crystallization process. The measurements were performed in the range of $25-190^{\circ} \mathrm{C}$ with a $10^{\circ} \mathrm{C} / \mathrm{min}$ heating and cooling cycle.

The observed behaviour of the PP can be evaluated by analysing the heat flow and the heat flux during thermal analysis. PP proved crystallization reaction according to the curves presented in figure 4 . The curve moved its pick when modified the cooling rate: the increasing of the cooling rate from $12^{\circ} \mathrm{C} / \mathrm{min}$ to double $\left(24^{\circ} \mathrm{C} / \mathrm{min}\right)$ decreased the temperature of the pick from $122.3^{\circ} \mathrm{C}$ to $117.2^{\circ} \mathrm{C}$. In the same time, a decreasing of the heat flow with about $10 \%$ (figure 4)

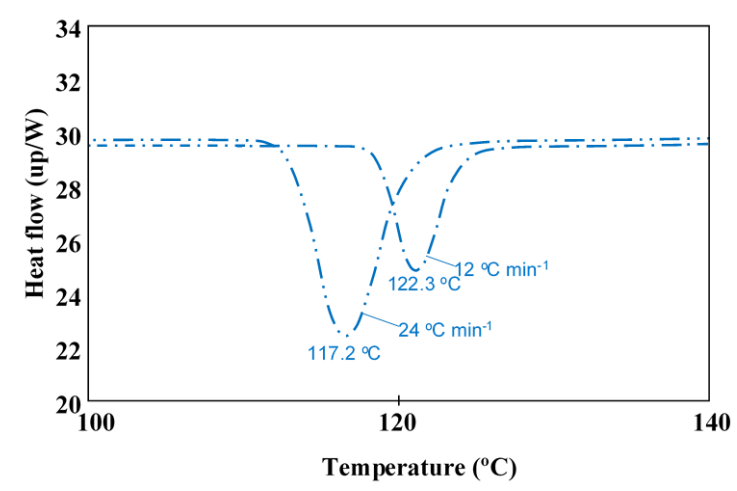

Fig. 4. Crystallization curve of PP

When compare to PLA the heat flux within PP proves about 15\% higher heat flux in the filament and 30\% higher in the deposited material (figure 5). That explains the difference between the viscosity of the two materials at the same temperature.

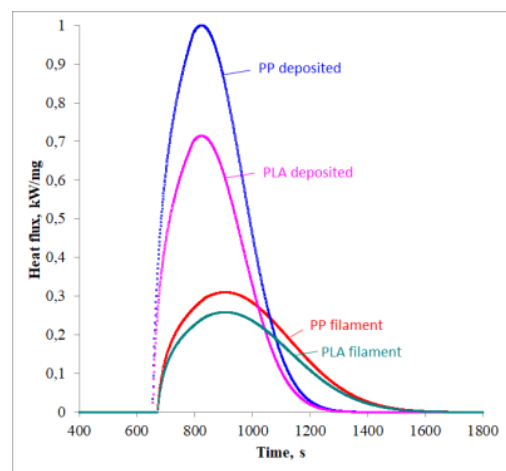

Fig. 5. Heat flux for the filament and for the deposited material

For FMD process a higher viscosity (in the range that permits a correct deposition) gives better results regarding the shape of the erected product. More, by applying an analysis of the elongation viscosity of PP, it can be observed a slight difference between the curve recorded before the melting of the filament and the curve of the deposited material, in the range of $1 \ldots 5 \mathrm{~s}$ (figure 6). Below $1 \mathrm{~s}$ and after $5 \mathrm{~s}$ the differences between the two curves increase, especially in long periods of testing.

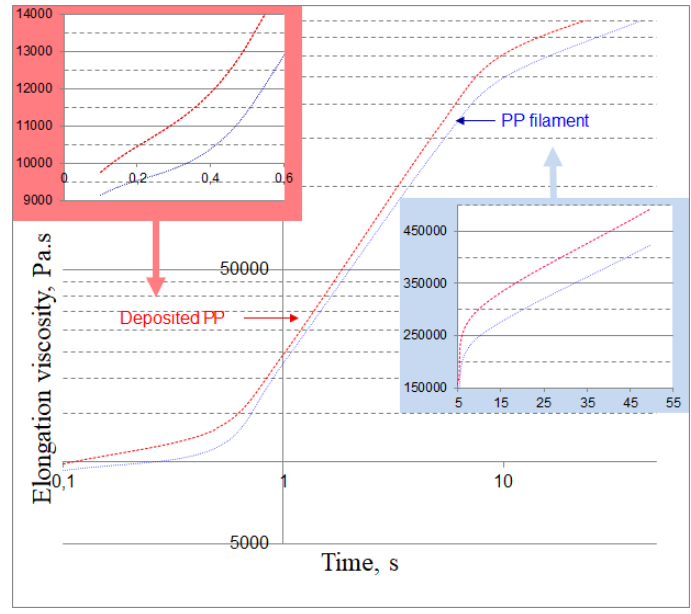

Fig. 6. Elongation viscosity at $188^{\circ} \mathrm{C}$ 
To better understand the behaviour of PP, when pass through the extrusion nozzle, dynamic shear rheology measurements. The test has been applied on samples deformed under $210 \mathrm{kN}$ at $190^{\circ} \mathrm{C}$. It was the plate/plate version and the used frequencies range was 0.01 to $100 \mathrm{rad} / \mathrm{s}$. From the test resulted information regarding the storage modulus and the complex viscosity of the both polymers in deposited status (figure $7 \mathrm{a}$ and b). Comparing the storage modulus of the two polymers, in deposited conditions (so, after the melting during printing process), it can be observed that the $\mathrm{PP}$ requires lower storage energy and that means that it has a lower viscosity for the entire range of frequencies. In the same time, the complex viscosities prove different behavior. Up to frequency of $10 \mathrm{rad} / \mathrm{s}$, the PLA keeps a higher viscosity, and between $10 \ldots 100 \mathrm{rad} / \mathrm{s}$ the situation is changed. PP shows a lower decreasing of the viscosity from $0.01 \ldots 100 \mathrm{rad} / \mathrm{s}$ than PLA. That means a higher stability of the PP's complex viscosity.

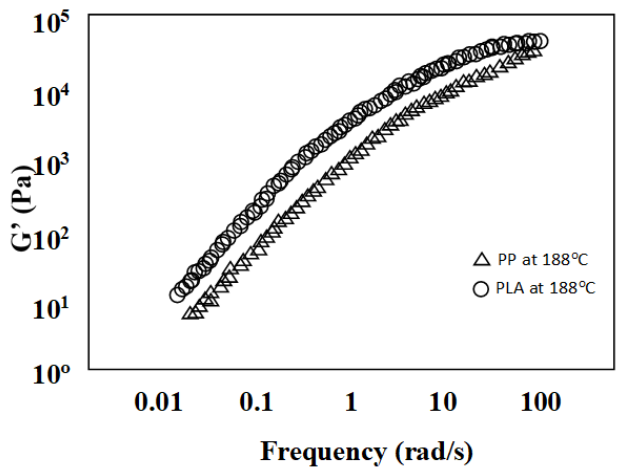

a.

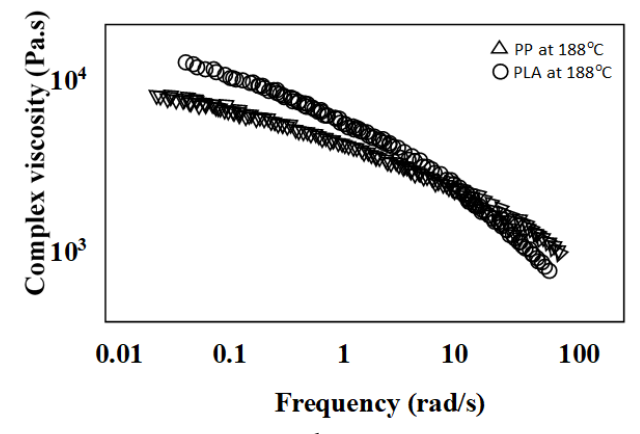

b.

Fig. 7. The storage modulus and the complex viscosity at $188^{\circ} \mathrm{C}$

Based on the obtained results it was considered that to improve the control of the deposition shape, it is necessary to reduce the extrusion temperature. A decreasing with $5 \%$, from $210^{\circ} \mathrm{C}$ to $200^{\circ} \mathrm{C}$, improved the behaviour of the PP filament. The specific string deposition became almost similar to the deposition of PLA (figure 8).

An advantage of that measure is the economy in power consumption.

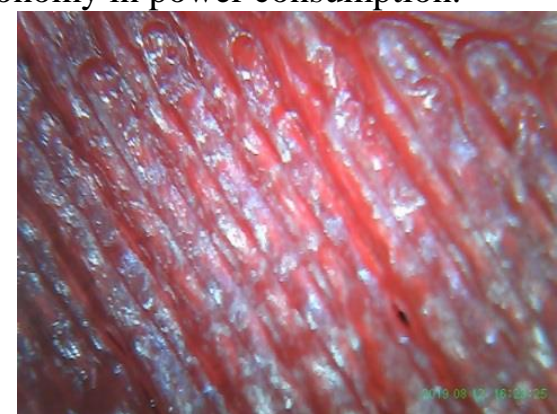

Fig. 8. Deposition shape in lower extrusion temperature

\section{Conclusions}

Concluding on the obtained results, it can be considered that PP can be used as filament material for deposition, but it has lower behaviour in 3D printing comparing to the PLA, due to its high viscosity, which reduces the possibility to control the edges of the deposited shapes. The heat flux in PP is 30\% higher than in PLA and that increases its fluidity. There is a difference between the elongation viscosity of the PP filament and the PP deposited by FDM process. After $5 \mathrm{~s}$ the deposited PP proves higher values for the elongation viscosity. $5 \ldots 7 \mathrm{~s}$ means exactly the time of crossing the nozzle and in that range of time the molten PP becomes more fluid than in the range of $1 \ldots 5 \mathrm{~s}$.

A possibility to improve the control of the deposition shape is to reduce the extrusion temperature and that brings other advantage, which is the decreasing of the power consumption. Anyway, the cost of PP is 4 times higher than the 
cost of PLA and it keeps PLA advantage against PP.

\section{References}

1.REDWOOD, B., SCHOFFER, F., GARRET, B., The 3D Printing Handbook: Technologies, design and applications, ISBN 978-90-8274850-5, 3D HUBS 2017.

2.MIHON, L., OSTOIA, D., NEGOITESCU, A., TOKAR, A., SIMULATION OF VEHICLE'S POWERTRAIN FOR PERFORMANCES EVALUATION, Annals ff DAAAM for 2009 \& Proceedings of the 20-th International DAAAM Symposium, Book Series: Annals of DAAAM and Proceedings, vol.20, 2009, p. 253-256

3.NEDELCU, D., COJOCARU, V., MICU, L.M., D FLOREA, F., MIHAI HLUSCU, M., Using of Polymers for Rapid Prototyping of anAxial Microturbine Runner and Wicked Gates, Mat.Plast., 56, no.2, 2019, pp. 454-459

4.COSMA, C., ROTAR, D., CIOANA, C., SERBAN, I., Redesigning Plastic Products, Mat. Plast., 48 , no. 3, 2011, p. $259-262$

5.TARNITA, D., BOBORELU, C., GEONEA, I., MALCIU, R., GRIGORIE, L., TARNITA, D.N., In vitro Implantation Technique Based on 3D Printed Prosthetic Prototypes, IOP Conf. Ser.: Mater. Sci. Eng. 374 012060, EUROINVENT ICIR 2018, vol. 374, 10.1088/1757-899X/374/1/ 012060

6.VASILESCU, M.D., Constructive and Technological Consideration on the Generation of Gear Made by the DLP 3D-Printed Method, Mat. Plast., 56, no. 2, 2019, p. 440-444

7.ZAPCIU, A., AMZA, C.G., RONTESCU, C., TASCA, G., 3D-Printed, Non-assembly, Pneumatically Actuated Mechanisms from Thermoplastic Materials, Mat. Plast., 55, no. 4, 2018, p. 517-520

8.MOTOMANCEA, A., BUCURESTEANU, A., PRODAN, D., Execution of Non-Metallic or Metallic Duplicates, Cast with 3D Scanners and 3D Printers, Mat. Plast., 56, no. 1, 2019, p. 6-10

9.FABIANI, Z., KADAR, K., PATONAY, L., NAGY, K., Application of 3D Printed Biocompatible Plastic Surgical Template for the Reconstruction of a Nasoalveolar Cleft with Preoperative Volume Analysis, Mat. Plast., 56, no. 2, 2019, p. 413-415

10.DIMONIE, D., Some Aspects Conditioning the Achieving of Filaments for 3D Printing from Physical Modified Corn Starch, Mat. Plast., 56, no. 2, 2019, p. 351-359

11.TRHLÍKOVÁ, L., ZMESKAL, O., PSENCIK, P., FLORIAN, P., Study of the thermal properties of filaments for 3D printing, AIP Conference Proceedings 1752, 040027 (2016); https://doi.org/ 10.1063/1.4955258

12.VAN ERP, T.B., Anisotropic plasticity in oriented semi-crystalline polymer systems, Master Thesis, Eindhoven University of Technology, 2008

13.MICU, L. M.,LAZAR, I.,CIRCIUMARU, A., BORDEASU, I., PIRVULESCU, L. D., HLUSCU, M., New Results Regarding Cavitation Behavior of Polymers Modified with Anorganic Substances Coated on Bronze Surfaces, Mat.Plast., 55, no. 3, 2018, p. 460-463

14.BORDEASU, I., CIRCIUMARU, A., POPOVICIU, M., LAZAR, I., BADARAU, R., GROZA, I., Cavitation Erosion Behavior on Thin Films of Polymer Blends Deposited Over Bronze Surfaces, Mat.Plast., 55, no. 53, 2018, p. 286-290

15.LAZAR, I., BORDEASU, I., CIRCIUMARU, A., MITELEA, I., BOCII, L.S., Behavior of Polymer Thin Films Deposed on Bronze Surfaces at Cavitation Erosion, Rev.Chim, (Bucharest), 69, no.10, 2018, p.2921-2927

16.MITElEA, I., VARZARU, N., BORDEASU, I., POPESCU, M., The High Frequency Welding Aptitude of Thermoplastic Polymers, Mat.Plast.,46, no.1, 2009, pp. 101-107

17.JEŘÁBEK, M., TSCHARNUTER, D., MAJOR, Z., RAVI-CHANDAR, K., LANG, R. W., Multiaxial yield behaviour of polypropylene, EPJ Web of Conferences 6, 03005 (2010) DOI: 10.1021/ma00045a034

18.GLEITER H., ARGON A. S., Plastic deformation of polyethylene crystals. Philosophical Magazine, 24, 71-80 DOI: $10.1080 / 14786437108216425$

19.SÉGUÉLA R., Plasticity of semi-crystalline polymers: Crystal slip versus melting-recrystallization. E-polymers, 7, 382-401 (2007). DOI: 10.1515/epoly.2007.7.1.382

20.WILHELM H., PARIS, A., SCHAFLER, E., BERNSTORFF, S., BONARSKI, J., UNGAR, T., ZEHETBAUER' M.J., Evidence of dislocations in melt-crystallised and plastically deformed polypropylene. Materials Science and Engineering: A, 387-389, 1018-1022 (2004).

21.HIRSCH J. R., WANG P. T., Texture and strength evolution in deformed polypropylene. Textures and Micro -structures, 13, 101-122 (1994). DOI: $10.1155 /$ TSM.13.101

22.BOYD R. H., Relaxation processes in crystalline polymers: Molecular interpretation - A review. Polymer, Volume 26, Issue 8, August 1985, Pages 1123-1133 DOI: 10.1016/0032-3861(85)90240-X

23.CHINNADURAI, T., ARUNGALAI VENDAN, S., RUSU, C.C., SCUTELNICU, E., Experimental investigations on the polypropylene behaviour during ultrasonic welding, Materials and Manufacturing Processes, Volume 33, 2018 - Issue 7, Pages 718-726 https://doi.org/10.1080/ 10426914.2017 .1303155

24.CHI, X., CHENG, L., LIU, W., ZHANG, X., LI, S., Characterization of Polypropylene Modified by Blending Elastomer and Nano-Silica Materials 2018, 11(8), 1321; https://doi.org/10.3390/ma11081321

25.CICIC, D.T., RONTESCU, C., AMZA, C.G., CHIVU, O.R., IACOBESCU, G., Qualitative and Quantitative Comparisons Concerning the Influence of Jointing Parameters on the Quality of the PPR Without Insertion Components Assembly, Mat. Plast., 53, no. 1, 2016, p. 38-41

26.MARIES, GH.R.E., Thermal Analysis of some physico-mechanical properties of PP used for Manufacturing of Performance Sport Items, Mat. Plast., 47, no. 4, 2010, p. 514-517

27.BOLOCAN, A., ION, D., CONSTANTINESCU, S., LUCA, A.-D., PĂDURARU, D.N., Randomised Trial Comparing Polypropylene Mesh and Polyvinylidene Fluoride Mesh in the Surgery, Mat. Plast., 49, no. 3, 2012, p. 209-211

28.SAVU, I.D., SAVU, S.V., SIRBU, N.A., Heat affected zones in polymer laser marking, JOURNAL OF THERMAL ANALYSIS AND CALORIMETRY, Volume: 115 Issue: 2 Pages: 1427-1437, 2014

29.SAVU, S.V., SAVU, I.D., CIUPITU, I., Thermal Analysis to Evaluate Ageing Process in Heated Tool and Electrofusion Welding of Polymer Pipes, Mod. Tech. In Ind. Eng. Book Series: Advanced Materials Research, Volume: 837 Pages: 190-+ 2014

30.RAPA, M., GROSU, E., GHIOCA, P.N., IANCU, L., SPURCACIU, B., PICA, A, GARDU, R., CINCU, C., Evaluation of Mechanical and Thermal Properties of PP Random Copolymer and Triblock Copolymer Blends, Mat. Plast., 53, no. 1, 2016, p. 68-72

31.GHIOCA, P., Recovered Polypropylene Composites with High Impact Strength, Mat. Plast., 54, no. 1, 2017, p. 18-21

32.MITSOULIS, E., Flow behaviour of a Polypropylene Melt in Capillary Dies, Int. Polymer Processing, XXXIII, 2018, p. 642-652

Manuscript received: 14.10 .2019 